University of Wollongong

Research Online

$1-1-2017$

The Introduction of Well-Being into the Curriculum of an Executive MBA

Program: The Sydney Business School as a Reflective Case Study

Lee Styger

University of Wollongong, Istyger@uow.edu.au

Lauren P. Richardson

University of Wollongong, laurenr@uow.edu.au

Follow this and additional works at: https://ro.uow.edu.au/buspapers

Part of the Business Commons

Research Online is the open access institutional repository for the University of Wollongong. For further information contact the UOW Library: research-pubs@uow.edu.au 


\title{
The Introduction of Well-Being into the Curriculum of an Executive MBA Program: The Sydney Business School as a Reflective Case Study
}

\author{
Abstract \\ There is hardly an established university anywhere in the world that does not have, or aspire to have, an \\ MBA program. Few universities, however, have dedicated Executive MBA (EMBA) programs and of those \\ universities that do, there is much confusion regarding what constitutes an EMBA. For example, some \\ university providers suggest that an EMBA is simply an extension of the full-time MBA program that is \\ offered to part-time students. Other university providers claim that an EMBA is a stand-alone and \\ differentiated program, consisting of a bespoke curriculum, designed for the mature executive.

\section{Keywords} \\ executive, curriculum, school, reflective, case, into, business, study, well-being, introduction, sydney, \\ program:, mba \\ Disciplines \\ Business

\section{Publication Details} \\ Styger, L. \& Richardson, L. P. (2017). The Introduction of Well-Being into the Curriculum of an Executive \\ MBA Program: The Sydney Business School as a Reflective Case Study. In B. Vogel, R. Koonce \& P. \\ Robinson (Eds.), Developing leaders for positive organizing : a 21st century repertoire for leading in \\ extraordinary times (pp. 263-272). Bingley, UK: Emerald Publishing Limited.
}




\title{
The Introduction of Wellbeing into the Curriculum of an Executive MBA Program - The Sydney Business School a Reflective Case Study
}

\author{
Dr Lee E J Styger \\ Executive MBA Director \\ Sydney Business School University of Wollongong \\ Lauren Richardson \\ Knowledge Manager \\ Sydney Business School University of Wollongong
}

There is hardly an established university anywhere in the world that does not have, or aspire to have, an MBA program. Few universities however, have dedicated Executive MBA (EMBA) programs and of those universities that do, there is much confusion regarding what constitutes an EMBA. For example some university providers suggest that an EMBA is simply an extension of the full time MBA program that is offered to part time students. Other university providers however claim that an EMBA is it a standalone and differentiated program, consisting of a bespoke curriculum, designed for the mature executive.

Our philosophy is that any EMBA program needs to be very different, with the subject matter designed and delivered with mature students in mind and delivered in an interactive, facilitated manner and incorporating a move from a traditional pedagogical inspired focus of disciplined focused subjects into a progressive style of delivery (Fornaciari and Lund Dean 2014, p.702). Our desired approach in designing the Sydney Business School's EMBA was to implement the six general principles of andragogy into the way the subject was implemented: "adults need to know "why" of learning; adults learn through trial-and-error experience; adults should own their own decisions about learnings; adults prefer learning that is immediately relevant to their lives; adults learn better from problem-based than content-based environments; and adults learn better with intrinsic versus extrinsic motives" (Knowles, 1997 in Fornaciari and Dean 2014, p.703). These principles transfer the authority, accountability and motivation towards the student, away from the lecturer.

In January 2013 the Australian Government developed the $2^{\text {nd }}$ edition of the Australian Qualifications Framework (AQF). The framework was designed to ensure that qualification titles across Australia are consistent and represent the same high standards of education. This national policy provided the guidelines for regulated education qualifications in Australia (The Commonwealth of Australia, 2012). This step change in the framework gave us the opportunity of designing a fundamentally different EMBA program from the grass roots up using Total Design Principles (Pugh, 1991) with a view to develop a mixed, yet balanced andragogical and heutagogical learning community, where the student body (average age 42 and average professional experience of 20 years) coexists and collaborates with the content delivers and professional educators.

To achieve this aim, it was necessary to breakdown the traditional speculums (silo) approach typically exploited in business education and design a curriculum that offered holistically themed delivery based on more readily accepted concepts of business (to the industry savvy student). This was achieved using a dual approach where the concept of commonly accepted business cycles (i.e. new business, growth business, mature business and declining business) (Schumpeter, 1961) were 
overlaid with fundamental principles of change (i.e. an evaluation of, "where are you now" - reality check, "what could you be" - envisioning, "what are you going to do about it" - setting the future intent) (Dunnette, 1990). This concept is illustrated in Figure 1.0. 


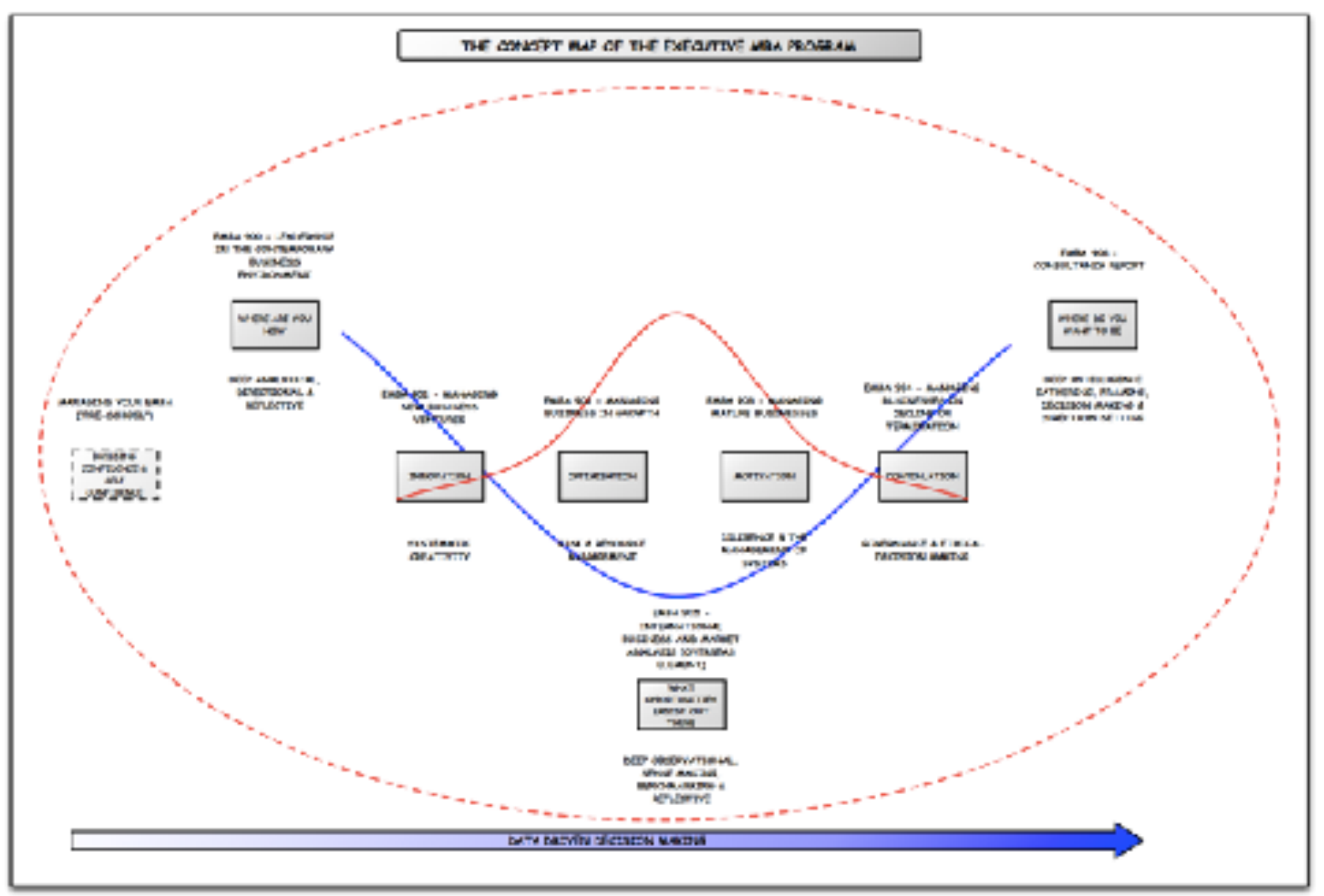

Figure 1.0 The Concept Map of the EMBA Program

Generally the concept of teaching themed holistic business concepts within the business cycle framework (i.e. a mini themed MBA in each subject) is well understood and accepted. However, 
the "custom shop V" of systematic transition is less understood, but paradoxically represents the real change engine within the EMBA program, albeit only when fully integrated with the themed subjects.

Many marketing messages of universities around the world would suggest that most MBA programs develop the business leaders of tomorrow (Bournemouth University, Cornell University, Deakin University, Griffith University, London Business School, Newcastle University, and Queens University). We would argue that our EMBA students are the business leaders of today, and it is the collaborative educational environment alongside the andragogical and heutagogical philosophy that fits so well with our mature students. Importantly, we have found that it is this education space where students can transition themselves and their organisations within a facilitated, social, peer supportive and professional context, whilst sharing all of life's challenges, traumas and triumphs along the way.

There remains however a challenge in the design of the program, insofar, as the teaching themed holistic business concepts within the business cycle framework can present a level of pushback from students from time to time when a part of the business cycle either not familiar to the student or as is more often the case a business cycle the student functions within currently, is delivered and the students present themselves with undue bias to the content, delivery mode and final outcome. Put simply, students initially assume for example that there is nothing new to be learned from managing a mature business because they currently function within one. This issue is contextualised below:

- EMBA 901 Managing New Business Ventures - Themed around systematic creativity focus "Innovation"

- EMBA 902 Managing Businesses in Growth - Themed around risk and resource management - focus "Optimisation"

- EMBA 903 Managing Mature Businesses - Themed around diligence and management of systems - focus "Motivation" (but often perceived to be a passive and lacklustre area of business management due to the axiom of mature businesses wanting to remain stable)

- EMBA 904 Managing Businesses in Decline or Termination - Themed around governance and ethical decision making - focus "Continuation"

The pushback from students relating to managing mature businesses initially became apparent during the prototyping stage of each of the subject prior to the EMBA program being offered. General responses included "We know how to do this" and "There is nothing new to learn and we are trying to find new approaches". We on-boarded these concerns at the subject design stage and went through additional ideation cycles from Design Thinking for our Managing Mature Businesses subject. We undertook the seven stages of the design thinking process: define research, ideate, prototype, choose, implement, and learn (Simon, 1969). Throughout this process, problems were framed, questions were asked, more ideas were created, and answers were developed. The path through this process was not strictly circular. Meinel and Leifer (2011) state "while the stages are simple enough, the adaptive expertise required choosing the right inflection points and appropriate next stage is a high order intellectual activity that requires practice and is learnable." What emerged from this process was a clear, but contemporary, emergence of issues relating to the future of work, the context of work within the community and wellbeing from both an individual and organisational perspective. 
Additional consultation with thought leaders in the business wellbeing and in the organisational psychology spaces led us to reframe the subject around personal and team motivation, wellbeing and mental fitness, where we turned the focus of the subject from that of the organisation to the inclusive performance of the individual self within it.

By engaging an consulting psychologist to lead the subject, a significantly different and positive outcome has resulted. EMBA 903 is delivered after EMBA 905 (the overseas "discovery" subject pivotal to the transformation process). Post the overseas subject, it was common for students to fall into a valley of quiet disappointment after being exposed to a myriad of challenging, emotive and motivational opportunities and then return to the reality of often lacklustre of negative culture within the businesses they functioned within. By taking the position of positive affirmation, EMBA 903 now encourages and supports students and even catapults students to determining what they are going to do about the positive transformation of themselves and their organisations. Importantly, by reinforcing the principle that the individual can only influence that which they are empowered to do, EMBA 903 fundamentally challenges the perspective of the student from a base of needing to be "best and right" into meaningful a contextual thinkers with a more pragmatic view of imbalance within the systems they operate.

Another challenge within the design and roll out of the program was appropriate coverage of issues relating to metal illness within the workplace. Mental illness remains one of the most entrenched areas of stigma in contemporary perceptions of disease. Many strategies have been used to combat stigma - the prejudice and discrimination. To start to combat this stigma the EMBA Students were introduced to language of mental fitness. The framework and language for the lectures was pulled from the concept of Mental Fitness (Robinson, Oades \& Caputi, 2014; Robinson \& Oades, 2016) which draws on a physical fitness analogy (strength, flexibility, endurance and team) to describe the variables and process of achieving measurable positive mental health outcomes. The mental fitness 'lens' was utilised to (a) reduce stigma when talking about mental health, (b) to emphasise the need for more proactive, preventative and holistic approaches to mental health at work, (c) to emphasisse a fit mind and body are equally important, and (d) to highlight that optimal mental health needs to be developed by way of regular intentional activities to form positive habits for sustainable change. The mental fitness analogy was extremely helpful in achieving buy-in from the students by using a language that was easy to understand and free of 'psychobabble.' It also provided students with an understanding that competitive edge can also be achieved at work through their own and others' level of mental health and wellbeing. What was achieved was a decreased in a lot of the stigma the students had around discussing mental health because they were able to view mental health in a new way i.e., through the lens of the physical fitness analogy.

Within the context of operational functionality, we have found wellbeing and mental fitness to be key contributors to the competitive performance of organisations, however, we are as yet finding via our EMBA students that there is little, appropriate, coverage outside of mainstream HR functions. As such, the inclusion of these themes within EMBA 903 Managing Mature Businesses comes as a breath of fresh air to many in the cohort. Moving forward into the remaining portions of the EMBA program, our challenge then becomes one of convincing the students that the delivery of concepts around positive psychology and wellbeing are sequenced as they are (and not as is then often requested sooner) because, to appreciate any gourmet product, the recipient must first develop a pallet of discerning taste and this is certainly the case with this subject. To put it another way, we are convinced that if we tried to lead with these concepts, mature students would not as yet be sufficiently open minded or indeed thirsty for the content and as such much of the impact of 
positive psychology and wellbeing would be discounted by the students before being given sufficient assimilation time - this may indeed mirror the case in businesses in general.

Overall, the student feedback around the inclusion of positive psychology and business wellbeing has been positive, comments such as:

- "I would also like to add that the learnings from this subject have been considerable for me and I believe the potential benefits for my organisation are significant"

- "I just wanted to write and say thank you for such an inspiring and fascinating subject. It has opened my eyes to so much and I feel I have grown from the experience, especially realising my strengths and weaknesses"

- "Whilst I have some of your time, I just want to say thank you for the last weekend of classes. I found it very informative and relevant to me and my current situation. I even found myself quoting, subconsciously, mental fitness in a text message to a fellow cohort member a few days later"

- "Firstly, I wanted to say thank you for last weekend's EMBA903 classes, it was great to be part of a program that prioritises teaching these kinds of things. I've been trying to bring in some of the elements around strengths based discussions to my team in the last week and its starting some great conversations"

In conclusion, our view is that an Executive MBA should be designed and delivered with the executive (or mature student) in mind. The holistic and themed design coupled with the sequencing of subject delivery is critical in delivering the maximum quality program that both challenges and importantly transforms the participants. At the heart of this transformation process, in terms of both sequence and design lays the principles of positive psychology and wellbeing. These principles are delivered at a time and in a manner that not only challenges the axiom of the student, but also helps make sense of the often conflicting nature of business from both the theoretical and applied nature. We are not aligned with the principle of discipline or silo teaching at the mature student level within a business context. Based on the work to date with our EMBA program, we conclude that the integration of these principles into a themed program provides significant gravitas compared to that of a standalone specialism.

A definite path to enlightenment, by design - overcoming biases to gain a greater insight and positive view.

\section{Questions for Discussion}

1. The authors of the case study discuss differences in the teaching and learning styles for mature and younger student cohorts. What could be the challenges, from a wellbeing point of view, if a student found themselves in the wrong teaching and delivery environment for themselves.

2. Do you consider that a higher educational program such as the Executive MBA should be designed around personal transformation and why do you consider that your view to to be the case. 
3. Is it conceivable that a higher educational program such as the Executive MBA could benefit mature students suffering from mild mental health conditions.

4. If you were asked to consult to a university considering including wellbeing and mental fitness into their curriculum what advise would you give.

5. From your research, and/or professional experience, who do you consider is the exemplar in holistically including wellbeing and mental fitness into their higher education business degrees.

\section{Reference list}

Bournemouth University 2016, 'Bournemouth University Business School', viewed 27/09/2016, , <https://www1.bournemouth.ac.uk/discover/faculties/faculty-management/our-departments/ bournemouth-university-business-school>

Cornell University 2016, 'Two-year MBA', viewed 27/09/2016, < $\underline{\text { http://www.johnson.cornell.edu/ }}$ Programs/Full-Time-MBA/Two-Year-MBA>.

Deakin University 2016, 'Masters of Business Administration', viewed 27/09/2016, < $\underline{\text { http:// }}$ www.deakin.edu.au/current-students/courses/course.php?course $=\mathrm{M} 701>$.

Dunnette, M. D. 1990, 'Blending the science and practice of industrial and organizational psychology: Where are we and where are we going?', In M. D. Dunnette \& L. M. Hough (Eds.), Hand book of industrial and organizational psychology (2nd ed., Vol. 1). Palo Alto, CA: Consulting Psychologists Press.

Fornaciari, CJ \& Lund Dean, K 2014, 'The 21st-Century syllabus: From pedagogy to andragogy', Journal of Management Education, vol. 38, no. 5, pp. 701-23.

London Business School 2016, ‘A unique career-changing experience', viewed 27/09/2016, > $<$ https://www.london.edu/education-and-development/masters-courses/mba\#.V-m7Ef196Uk $>$.

Newcastle University 2016, 'Masters of Business Administration MBA', viewed 27/09/2016, < http://www.ncl.ac.uk/postgraduate/courses/degrees/master-of-business-administration-mba/ \#profile> .

Nicholas, N 2016 'Griffith launches new MBA scholarship with Queensland Business Monthly ',Griffith University, August 26"th, viewed 27/09/2016, < $\underline{\text { https://app.secure.griffith.edu.au/news/ }}$ 2016/08/26/griffith-launches-new-mba-scholarship-with-queensland-business-monthly/> .

Plattner, H; Meinel, C; Leifer, L, (eds.) 2011. Design thinking: understand, improve, apply. Understanding innovation. Berlin, Heidelberg:Springer-Verlag. pp. xiv-xvi.

Pugh, S 1991, Total design : integrated methods for successful product engineering, Wokingham, England ; Reading, Mass. : Addison-Wesley Pub. Co. 
Queens University 2008, 'Queens School of Business Annual report', viewed 27/09/2016, < $\underline{\text { https:// }}$ smith.queensu.ca/ConversionDocs/Annual_Report_2008.pdf>

Schumpeter, J.A. 1961, The theory of economic development: an inquiry into profits, capital, credit, interest, and the business cycle translated from the German by Redvers Opie, New York: OUP.

Simon, H 1969, The Sciences of the Artificial, Cambridge, MIT Press.

The Commonwealth of Australia 2012, TEQSA Glossary of Terms, viewed 30/12/2015, <http:// www.teqsa.gov.au/media-publications/glossary>. 